\title{
Does glutamine concentration depends on the type of the operation?
}

\author{
Aleksandra Rozowicz ${ }^{1}$, Krzysztof Kusza $^{2}$, Marlena Jakubczyk ${ }^{1}$, Piotr Kośliński ${ }^{3}$, Paulina \\ Szatkowska-Wandas ${ }^{3}$, Katarzyna Wawrzyniak ${ }^{1}$, Marcin Koba ${ }^{3}$, Jacek Szopinski ${ }^{4}$ and Pawel \\ Jakubczyk $^{5}$ \\ 1* Department of Anaestesiology and Intensive Therapy, UMK in Torun - Collegium Medicum in Bydgoszcz, \\ 86-094 Bydgoszcz, Poland; arozowicz@op.pl \\ 2 Department of Anaestesiology and Intensive Therapy, University of Medical Sciences in Poznan, 86-094 \\ Bydgoszcz, Poland \\ 3 Department of Toxicology, UMK in Torun - Collegium Medicum in Bydgoszcz, 86-094 Bydgoszcz, Poland \\ 4 Department of Anaestesiology and Intensive Therapy, UMK in Torun - Collegium Medicum in Bydgoszcz, \\ 86-094 Bydgoszcz, Poland \\ $510^{\text {th }}$ Military Research Hospital and Polyclinic. Independent Public Healthcare Centre in Bydgoszcz \\ * Correspondence: arozowicz@op.pl; Tel.: +48-52-52 - 5854750
}

\begin{abstract}
Glutamine is the main amino acid which is substrate for gluconeogenesis in postoperative period. It is suggested that this leads to a substantial and a long-term decline in glutamine concentration. Glutamine is a source of energy for the synthesis of nucleotides, lymphocytes and cells of gastrointestinal tract. In this study, 79 patients were qualified to a coronary artery bypass surgery (Group I) or a surgery in the large intestine area (Group II). The objectives of this study were: evaluation of the impact of surgical procedures on the serum concentration of glutamine of the operated patients, assessment of gender, weight and BMI impact on glutamine concentration and analysis of the correlation between glutaminę serum concentration and laboratory parameters. The mean concentration of glutamine before surgery, the 3rd and 5th day after surgery was higher in Group I. CRP level in the 3rd and 5th postoperative day was higher in Group II. There were no significant differences betweengroups when it comes to BMI and the concentration of CRP $(p<0.05)$. Glutamine concentration depends on the severity of inflammation, the operated body cavity and the intensified catabolism which results from different pathophysiology of digestive system diseases and coronary arterial disease.
\end{abstract}

Keywords: glutamine; perioperative period; bypass surgery; intestine surgery; HPLC

\section{Introduction}

Metabolic response to stress (ie. a surgical procedure) significantly affects protein turnover in the body. It is regulated by catabolic hormones such as catecholamines, corticosteroids and glucagon. In addition, activities of cytokines, antioxidants, and eicosanoids change. Supplying energy to the cells which significantly increase their activity is the paramount goal in the stress- or surgeryinduced illness. In the postoperative period demand for protein increases significantly - even up to $300 \%$ in reference to the demands under physiological conditions [1]. Due to a widespread use and occurrence of proteins in the body, the deficiency of particular amino acids may contribute to disturb many biochemical processes. As a result of homeostasis deterioration it can lead to dysfunction of individual systems such as immunological, digestive, hematopoietic or neuroendocrine system.

Glutamine is the main amino acid which is known to be substrate for gluconeogenesis in postoperative period. It is suggested that this leads to a substantial and a long-term decline in glutamine concentration. It may be a co-factor leading to immunosuppression immediately after a 
surgery, because glutamine is a source of carbon and nitrogen for the synthesis of nucleotides, lymphocytes and cells of gastrointestinal tract [2]. Another factor influencing the deficit of glutamine is the lowered rate of its synthesis - hence it is called a conditionally essential amino acid [3]. Glutamine synthetase expression depends on the total concentration of glutamine in the body. The glutamine reserves in muscles are directly proportional to the total muscle mass. The bigger muscle mass is the higher amount of glutamine is accessible for metabolic processes. Therefore it is suggested that people who retain a relatively large muscle mass may have a greater ability to regenerate during metabolic stress of various origin (surgery, infection) $[4,5,6]$. Apart from a pharmacotherapy, a proper nutritional therapy is one of the elements that modulate the body's response to injury, providing essential building and energy nutrients, as well as vitamins and minerals necessary to maintain homeostasis. Glutamine is the source of energy for rapidly dividing cells, including villi cells of the small intestine (enterocytes) and large intestine (colonocytes) [7]. This amino acid has a beneficial effect on the integrity of intestinal mucosa and prevents bacterial translocation $[8,9]$. Additionally, glutamine prevents from atrophy of intestinal epithelial cells, stimulates their proliferation and reduces the permeability of the intestinal epithelium. It determines the integrity of particular building structures [10,11]. Glutamine stimulates appropriate functioning of the immune system connected with gastrointestinal tract (GALT- Gut-Associated Lymphoid Tissue). GALT is responsible for protecting human gastrointestinal tract against antigens and extraneous micro-organisms which can penetrate into it. Moreover, it secures the balance of bacterial flora as well as the integrity of the mucosa. Glutamine is preferred nutrient for rapidly dividing cells, which in relation to function of the immune system is important for lymphocyte population [7]. Glutamine's impact on the functioning of the immune system finds expression mainly in the quantitative changes in T lymphocytes population [12]. Glutamine is also essential source of energy used to produce macrophages, and may trigger anti-inflammatory effect indirectly by having the influence on production of IL- 6 (Interleukin-6) and TNF- $\alpha$ (Tumor Necrosis Factor $\alpha$ ) [13,14]. Glutamine deficiency probably increases the rate of cells apoptosis and reduces the ability of the immune system reaction to pro-inflammatory cytokines [15]. The aim of this study was to measure changes in glutamine concentration in blood serum depending on the type of the surgery performed. The research also introduced the analysis of the relationship between glutamine concentration in blood serum and examined laboratory (C-reactive protein, albumin, total protein), anthropometric parameters, taking into consideration the particularly selected inflammation indicators (C-reactive protein).

\section{Materials and Methods}

\section{Patients selection}

The research was conducted in 2015 and 2016, among 79 inpatients aged between 35 and 84 (an average age $59 \pm 12$ ). Men accounted $52 \%$ for all patients $(\mathrm{N}=41)$ and women accounted $48 \%$ for all patients $(\mathrm{N}=38)$ who were hospitalized at the University Hospital in Bydgoszcz. They all were qualified to a coronary artery bypass surgery (Group I- 40 patients) or a surgery of the large intestine (Group II - 17 patients).

Group I - patients scheduled for OPCABG (Off Pump Cardiac Artery Bypass Grafting). It is a surgical procedure for ischaemic heart disease.

Group II - patients scheduled for right hemicolectomy. This is an operation to remove the right side of the colon in group of patients with colon cancer.

Patients selected to the study must have fulfilled the following conditions:

1. the surgery of the gastrointestinal tract or the coronary artery bypass surgery without cardiopulmonary bypass had to be performed as scheduled

2. good nutritional status before the surgery ( $<3$ points in the scale of NRS 2002)

The excluding criteria were as follows:

1. long-term comorbidities: diabetes type 1 and 2, liver diseases, autoimmune disorders

(to standardize the group of patients),

2. nutrition disorders before the surgery (protein-energy malnutrition), 
3. a lack of consent to participate in the study.

II. Serum collection

The material for this research was peripheral blood collected in the morning before surgery and on postoperative days 3 and 5. Before surgery we measured: the serum glutamine concentration, Creactive protein level, nutritional status before surgery (total protein level and albumin concentration in serum) in both group. On postoperative days we measured: the serum glutamine concentration and C-reactive protein.

\section{Chemicals and Materials}

AccQ Fluor Reagent Kit (Waters), amino acid standards (Waters), amino acid standards (Waters), internal standard $\alpha$-aminobutyric acid (Sigma Aldrich) acetonitrile and methanol (Sigma Aldrich). Deionized water, purified with Direct-QUV (Millipore, France) system was used for all aqueous solutions.

\section{Sample preparation}

Preparation of serum for chromatographic analysis included deproteinization and derivatisation of the sample. For the serum deproteinization, Phree Phospholipid Removal Solutions, with solid phase extraction kit, were used. The prepared serum samples were subjected to a derivatisation procedure in accordance with the Waters AccQ Tag method.

\section{$V$. Chromatographic method}

Chromatographic analysis, which was aimed at measuring the glutamine concentration in the examined samples, was carried out using the high-performance liquid chromatography (HPLC) with fluorescence detection using AccQ Tag column (Waters). An example chromatographic separation of amino acids, using the AccQ Fluor Reagent Kit.

\section{Statistical analysis}

Statistical analysis was carried out using a software called STATISTICA 12.0 (StatSoft). Differences considered to be statistically significant were those with the value of $p<0.05$. Compatibility of distribution of particular features with the normal distribution was examined by the Shapiro-Wilk test $(X \pm S D)$. Incompatible parameters' values with the normal distribution were presented as median $(\mathrm{Me})$, lower and upper quartile (Q1-Q3). The analysis of differences between the measured parameters in the respective groups was conducted using t-student test for parameters which were compatible with the normal distribution and non-parametric U Mann-Whitney test for parameters which varied from the normal distribution. For the analysis of differences in specified subgroups we used test of Wilcoxon or Spearman coefficient (R).

The study was approved by the Bioethics Committee of the Nicolaus Copernicus University in Torun, Ludwik Rydygier Collegium Medicum in Bydgoszcz (KB 355/2013).

\section{Results}

The results for preoperative period are presented in Table 1. The analysis of the glutamine concentration as well as selected anthropometric and laboratory parameters in Group IOPCABG surgery (Off Pump Cardiac Artery Bypass Grafting) and in Group II (large intestine surgery) shows statistically significant higher level of glutamine in Group I $(p=0.002)$. There were no significant differences between both groups when it comes to body mass index (BMI) and the concentration of C-reactive protein (Table 1). 
141 Table 1. The concentration of glutamine and selected anthropometric and laboratory parameters in 142 Groups I and II preoperatively

143

\begin{tabular}{|c|c|c|c|c|c|}
\hline \multirow[t]{2}{*}{ Parameter } & \multicolumn{2}{|c|}{$\begin{array}{c}\text { I Group } \\
\text { (before OPCABG) } \\
\mathrm{N}=40\end{array}$} & \multicolumn{2}{|c|}{$\begin{array}{c}\text { II Group } \\
\text { (before the surgery in the large } \\
\text { intestine area) } \\
\mathrm{N}=17\end{array}$} & \multirow[t]{2}{*}{$P$} \\
\hline & $\begin{array}{c}\mathrm{Me} / \\
\mathrm{X} \\
\end{array}$ & $\begin{array}{c}\text { Q1;Q3/ } \\
\pm \mathrm{SD}\end{array}$ & $\begin{array}{c}\mathrm{Me} / \\
\mathrm{X}\end{array}$ & $\begin{array}{c}\mathrm{Q} 1 ; \mathrm{Q} 3 / \\
\pm \mathrm{SD}\end{array}$ & \\
\hline $\begin{array}{l}\text { Glutamine } \\
{[\mathrm{pmol} / \mu \mathrm{l}]}\end{array}$ & 85.43 & $65.62 ; 104.39$ & 60.70 & $37.74 ; 72.89$ & 0.001 \\
\hline $\begin{array}{l}\text { Age } \\
\text { [years] }\end{array}$ & 65.20 & \pm 7.13 & 64.58 & \pm 12.06 & 0.812 \\
\hline $\begin{array}{c}\text { BMI } \\
{\left[\mathrm{kg} / \mathrm{m}^{2}\right]}\end{array}$ & 28.30 & $26.35 ; 30.08$ & 25.65 & $23.94 ; 28.06$ & 0.008 \\
\hline Albumin [mg/dl] & 4.31 & \pm 0.22 & 4.07 & \pm 0.26 & 0.001 \\
\hline $\begin{array}{c}\text { Total protein } \\
{[\mathrm{mg} / \mathrm{dl}]}\end{array}$ & 7.20 & $6.95 ; 7.40$ & 6.80 & $6.40-7.00$ & 0.002 \\
\hline $\begin{array}{l}\text { CRP } \\
{[\mathrm{mg} / \mathrm{l}]}\end{array}$ & 1.09 & $0.68 ; 1.27$ & 1.05 & $0.52 ; 1.20$ & 0.588 \\
\hline
\end{tabular}

144 Pearson correlation analysis in the general examined group showed a positive correlation $(\mathrm{r}=0.385)$ 145 and statistically significant correlation between albumin and glutamine concentration $(p=0.005)$ 146 before surgery.

147 Patients from Group I had higher concentration of glutamine on the 3rd postoperative day in 148 comparison to patients from Group II. However, these differences were not statistically significant. 149 On the other hand, we observed higher concentration of C-reactive protein in Group I than Group II $150 \quad(\mathrm{p}=0.047)$ (Table 2). On the 5th postoperative day, statistically significant higher level of glutamine 151 was observed in Group I ( $p=0.029$ ). There was no statistically significant difference in the 152 concentration of CRP between groups. (Table 3).

153 Table 2. Comparison of the glutamine concentration and laboratory parameters in examined groups 154 (on the third day after the surgery)

155

\begin{tabular}{|c|c|c|c|c|c|}
\hline \multirow[t]{2}{*}{ Parameter } & \multicolumn{2}{|c|}{$\begin{array}{c}\text { I Group } \\
\text { (after OPCABG) } \\
\text { N }=40\end{array}$} & \multicolumn{2}{|c|}{$\begin{array}{c}\text { II Group } \\
\text { (after the surgery in the large } \\
\text { intestine area) } \\
\mathrm{N}=17\end{array}$} & \multirow[t]{2}{*}{$p$} \\
\hline & $\begin{array}{c}\mathrm{Me} / \\
\mathrm{X}\end{array}$ & $\begin{array}{l}\text { Q1;Q3/ } \\
\pm \mathrm{SD}\end{array}$ & $\begin{array}{c}\mathrm{Me} / \\
\mathrm{X}\end{array}$ & $\begin{array}{c}\mathrm{Q} 1 ; \mathrm{Q} 3 / \\
\pm \mathrm{SD}\end{array}$ & \\
\hline $\begin{array}{l}\text { Glutamine } \\
{[\mathrm{pmol} / \mu \mathrm{l}]}\end{array}$ & 70.35 & $47.33 ; 96.32$ & 63.65 & $41.99 ; 80.34$ & 0.326 \\
\hline $\begin{array}{c}\text { CRP } \\
{[\mathrm{mg} / \mathrm{l}]}\end{array}$ & 189.13 & $147.14 ; 231.77$ & 130.01 & $57.21 ; 173.13$ & 0.047 \\
\hline
\end{tabular}


Table 3. Comparison of the glutamine concentration and laboratory parameters in examined groups (on the fifth day after the surgery)

\begin{tabular}{|c|c|c|c|c|c|}
\hline \multirow[t]{2}{*}{ Parameter } & \multicolumn{2}{|c|}{$\begin{array}{c}\text { I Group } \\
\text { (after OPCABG) } \\
\text { N }=40\end{array}$} & \multicolumn{2}{|c|}{$\begin{array}{c}\text { II Group } \\
\text { (after the surgery in the large } \\
\text { intestine area) } \\
\mathrm{N}=17\end{array}$} & \multirow[t]{2}{*}{$p$} \\
\hline & $\begin{array}{c}\mathrm{Me} / \\
\mathrm{X}\end{array}$ & $\begin{array}{c}\mathrm{Q} 1 ; \mathrm{Q} 3 / \\
\pm \mathrm{SD}\end{array}$ & $\begin{array}{c}\mathrm{Me} / \\
\mathrm{X}\end{array}$ & $\begin{array}{c}\mathrm{Q} 1 ; \mathrm{Q} 3 / \\
\pm \mathrm{SD}\end{array}$ & \\
\hline $\begin{array}{l}\text { Glutamine } \\
{[\mathrm{pmol} / \mu \mathrm{l}]}\end{array}$ & 81.79 & $61.57 ; 114.82$ & 54.31 & $32.60 ; \quad 80.98$ & 0.029 \\
\hline $\begin{array}{c}\text { CRP } \\
{[\mathrm{mg} / \mathrm{l}]}\end{array}$ & 45.55 & $29.60 ; \quad 137.00$ & 92.58 & $54.50 ; 125.44$ & 0.450 \\
\hline
\end{tabular}

\section{Discussion}

One of the elements of comprehensive approach to surgical treatment is to draw attention to the proper nutritional status of patients. Nowadays, knowledge of the physiopathology of phenomena occurring in the digestive system in the perioperative period has significantly increased. The alimentary tract and GALT play an important role in mechanisms which help to maintain system homeostasis. Glutamine in the postoperative period is mainly used by enterocytes and GALT cells, so that it consequently improves the immune response of the system [16]. In recent years, much attention has been paid to research aimed at increasing the effectiveness of nutritional therapy in the perioperative period, with particular focus on potentially immunomodulatory components.

During an assessment of the concentration of glutamine in the preoperative period in the inpatients' groups (Group I vs. Group II), it was observed that statistically significant higher level of glutamine concentration occurred among the patients admitted for OPCABG (Group I), compared to the ones admitted to comply right sided hemicolectomies (Group II). A factor that may influence the increase in glutamine concentration in blood serum in Group I can be the long-term inflammation in intima and in the middle velum of coronary arteries. Gastrointestinal tract diseases may potentially be associated with chronic disorders of digestion and absorption of nutrients, which may lead to the occurrence of nutrients' deficiencies, including a reduction in glutamine concentration that plays a key role in the proper functioning of the intestinal villi. Xu et al. investigate the protective effect of glutamine supplementation on intestinal villi in hypobaric hypoxia environment vs. normal control group. Hypoxia may induce severe primary intestinal barrier dysfunction, because intestinal microvilli are extremely sensitive to that parameters [17]. Glutamine play a special role in maintaining mucosal structure and probably may have a special effects on the maintenance of tight junction and permeability of the intestinal mucosa. In conclusion glutamine may play key role in protecting the human intestinal mucosal [18].

Hensley et al. compared glutamine metabolism in heath and cancer. Glutamine consumption occurs largely in the kidney and gut, particularly the small intestine, in group of healthy people. Cancer change pathway of glutamine metabolism from gut and kidney to skeletal muscle and greatly increases the release of glutamine into the circulation. Simultaneously, intramuscular glutamine pool are depleted in association with loss of lean muscle mass, which can remind cancer-cachexia syndrome [19]. 
191 The study Nakazato et al., showed also lower values of the glutamine concentration in blood serum 192 in the control group in relation to the group of all examined patients with anorexia nervosa. One 193 possibility is that in anorexia nervosa, raised serum glutamine is a compensatory metabolic 194 response due to malnutrition[20]. In this study, basing on the results, pose a statement that 195 glutamine may be a biomarker of the systemic inflammation's severity, hence the increased values 196 in the control group compared to the group of healthy individuals can be justified by a generalized 197 atherosclerosis among patients from the Group I.

198

199

200

201

202

203

204

205

206

207

208

In the preoperative period, the own study shows statistically significant and directly proportional relation between glutamine and albumin concentration. The quoted studies which involved patients undergoing surgeries of the gastrointestinal tract, especially in the colon area, also indicated the interrelation between glutamine and albumin concentration [21]. Experimental studies on rats fed parenterally with a mixture of standard amino acids, or a mixture of amino acids with glutamine have shown significantly higher concentration of albumin in the group supplemented with glutamine [22]. In the perioperative period, the importance of glutamine for albumin concentration may result from the fact that glutamine participates in the proper functioning of the immune system and supports anti-inflammatory processes. Lack of inflammation does not move glutamine and albumin metabolism in the direction of protein reserves consumption to produce acute phase proteins.

The analysis of glutamine concentration was conducted also on the third and the fifth day after the surgery. In our study the decline in glutamine concentration in blood serum was observed among inpatients from Group I (OPCABG) on the third day after the surgery, compared to the preoperative period. The studies performed on patients undergoing surgeries, have shown the influence of the extent of the surgery on the glutamine concentration reduction. Concentration decrease of this amino acid comes after the injury in the short time, as a result of glutamine distribution for increased metabolic needs of the immune system [23].

In our study, the analysis of glutamine concentration on the 5th postoperative day in Group I showed an upward trend and a return to output values observed before performing the procedure. The increase in glutamine concentration up to the preoperative level may suggest an endogenous glutamine's reserves rebuilding.

An additional factor influencing the return to output values may be the fact that the operation included only the chest area without disrupting the continuity of the intestinal lumen and without temporary motility inhibition caused usually by abdominal surgery.

Moreover, the glutamine concentration in blood serum on the 3rd postoperative day in Group II has increased compared to pre-surgery values. Similar results were obtained by Poschke team, studying patients with breast cancer during the perioperative period. According to researchers, the increase in some amino acids concentration, including glutamine, was dependent on the scope of the surgery. The hypothesis explaining the fact of the higher glutamine concentration in blood serum after surgery may be mobilization of glutamine reserves associated with muscle tissue proteins and transporting them to peripheral blood to use amino acid by rapidly dividing cells such as enterocytes and lymphocytes [24].

Among inpatients from Group II, operated on the large intestine, the analysis of glutamine concentration on the fifth day after the surgery has revealed that the concentration of this amino acid decreased compared to the output value and the value obtained on the third day after the surgery. The decrease of glutamine concentration in this group of patients, in reference to previous analyses, suggests increased system requirements for this amino acid, resulting from intensified production of proinflammatory cytokines and acute phase proteins, which is typical for surgeries of the abdominal cavity. 
A meta-analysis of randomized studies, including patients undergoing abdominal surgery fed parenterally with standard formula and the group of patients fed parenterally with addition of Lalanyl-L-glutamine showed the benefits of using glutamine such as shorter hospital stay and less infections. However, there was no reduction in mortality in the group that received the addition of glutamine to the nutrition formula [25].

C-reactive protein (CRP) as an index of inflammation can be considered as a parameter reflecting the intensification of inflammation [26]. Activation of pro-inflammatory response in reaction to a surgery had the impact on glutamine concentration examined on the third day after the surgery. The increase of C-reactive protein concentration was accompanied by reduction in glutamine concentration in blood serum. The study of Pan et al. also introduced an inverse relationship: with an increase of CRP concentration the glutamine concentration decreases [22]. Changes in these parameters confirm the consumption of glutamine for the production of pro-inflammatory proteins in response to an injury. Due to the fact that glutamine is the energy source for rapidly proliferating cells, it has the beneficial impact on proper functioning of the immune system.

The decrease in CRP concentration was observed on the fifth day after the surgery. The decline in CRP concentration was higher in the group of inpatients who had undergone the surgery of coronary artery bypass in reference to the values recorded in the group of inpatients after the surgery of the large intestine. The Group I obtained nearly fourfold decrease in CRP level concerning the value reached on the third postoperative day. In the Group II CRP level also decreased, however in this group the decrease of C-reactive protein concentration wasn't so high.

In our study, patients undergoing the OPCABG surgery were extubated and left to spontaneous breathing on average 16 hours after the surgery. On the day of extubation oral feeding was initiated, beginning from water to complete diet according to tolerance. Patients undergoing the large intestine surgery, were extubated and left to spontaneous breathing two hours after the surgery. This condition is connected to the acceleration of metabolism and the activation the respiratory muscles that is further associated with the maintenance of a strict diet as well as with a negative energy balance and nitrogenous balance. The beginning of feeding using gastrointestinal tract took place on average on the fourth day after surgery in Group II. The nutrition started from a hypocaloric liquid diet which was successively moved to normal diet within few days. The diet might have been one of the factors that leaded to quicker increase in glutamine concentration after surgery and faster return to the normal glutamine levels in the blood serum.

\section{Conclusions}

Comparing the patients who undergo the surgery of large intestine with the patients who undergo the coronary artery bypass grafting, it is concluded that the former group of patients showed the lower glutamine concentration in blood serum. It may result from the violation of the integrity of the gastrointestinal tract that consequently leads to prolong time to return to its physiological function. Glutamine concentration depends on the severity of inflammation. The lower glutamine concentration in blood serum observed in patients undergoing the surgery in the area of large intestine suggest that the system is demanding for glutamine in perioperative period. The demand for glutamine depends on the operated body cavity and the intensified catabolism which results from different pathophysiology of digestive system diseases and coronary arterial diseases.

Author Contributions: A.R., M.J. and K.K. conceived and designed the experiments; A.R., M.J. performed the experiments; M.J. and P.J. analyzed the data; P.K., P.S.-W. and P.K. contributed reagents/materials/analysis tools; A.R., K.W. and J.S. wrote the paper. All authors read and approved the final version of the manuscript.

Conflicts of Interest: The authors declare no conflict of interest. 


\section{References}

1. Sobotka L. Basic of clinical nutrition. Prague: Galen; 2013.

2. Oliveira GP, Dias CM, Pelosi P, Rocco PR. Understanding the mechanisms of glutamine action in critically ill patients. An Acad Bras Cienc. 2010;82(2):417-430. doi: 10.1590/S0001-37652010000200018

3. Labow BI, Souba WW. Glutamine. World J Surg. 2000;24(12):1503-1513.

4. Zheng Y, Li F, Qi B, Luo B, Sun H, Liu S, Wu X. Application of perioperative immunonutrition for gastrointestinal surgery: a meta-analysis of randomized controlled trials. Asia Pac J Clin Nutr. 2007;16(1):253-257.

5. Braga M, Ljungqvist O, Soeters P, Fearon K, Weimann A, Bozzetti F. ESPEN Guidelines on Parenteral Nutrition: surgery. Clin Nutr. 2009;28(4):378-386. doi: 10.1016/j.clnu.2009.04.002

6. Weimann A, Braga M, Harsanyi L, Laviano A, Ljungqvist O, Soeters P et al. ESPEN Guidelines on Enteral Nutrition: Surgery including organ transplantation. Clin Nutr. 2006;25(2):224-244. doi: 10.1016/j.clnu.2006.01.015

7. Schlemmer M, Suchner U, Schapers B, Duerr EM, Alteheld B, Zwingers T, Stehle P, Zimmer HG. Is glutamine deficiency the link between inflamation, malnutrition, and fatigue in cancer patients? Clin Nutr. 2015;34:1258-1265. doi: 10.1016/j.clnu.2014.12.021

8. Wang B, Wu G, Zhou Z, Dai Z, Sun Y, Ji Y et al. Glutamine and intestinal barrier function. Amino Acids. 2015;47:2143-2154. doi: 10.1007/s00726-014-1773-4

9. Neu J, DeMarco V, Li N. Glutamine: clinical applications and mechanisms of action. Curr Opin Clin Nutr Metab Care. 2002;5:69-75.

10. Thomson AB, Keelan M, Thiesen A, Clandinin MT, Ropeleski M, Wild GE. Small bowel review: diseases of the small intestine. Dig Dis Sci. 2001;46:2555-2566.

11. Mondello S, Galuppo M, Mazzon E, Domenico I, Mondello P, Carmela A, Cuzzocrea S. Glutamine treatment attenuates the development of ischaemia/reperfusion injury of the gut. Eur J Pharmacol. 2010;643(2-3):304-315. doi: 10.1016/j.ejphar.2010.06.044.

12. Engel JM, Pitz S, Mühling J, Menges T, Martens F, Kwapisz M, Hempelmann G. Role of glutamine administration on T-cell derived inflammatory response after cardiopulmonary bypass. Clin Nutr. 2009;28(1):15-20. doi: 10.1016/j.clnu.2008.08.007.

13. O'Riordain MG, Fearon KC, Ross JA, Rogers P, Falconer JS, Bartolo DC, Garden OJ, Carter DC. Glutaminesupplemented total parenteral nutrition enhances T-lymphocyte response in surgical patients undergoing colorectal resection. Ann Surg. 1994;220(2):212-221.

14. Parry-Billings M, Evans J, Calder PC, Newsholme EA. Does glutamine contribute to immunosuppression after major burns? Lancet. 1990;336(8714):523-525.

15. Eliasen MM, Brabec M, Gerner C, Pollheimer J, Auer H, Zellner M, Weingartmann G, Garo F, Roth E, Oehler R. Reduced stress tolerance of glutamine-deprived human monocytic cells is associated with selective down-regulation of Hsp70 by decreased mRNA stability. J Mol Med. 2006;84(2):147-158. doi: 10.1007/s00109-005-0004-6.

16. Li J, King BK, Janu PG, Renegar KB, Kudsk KA. Glycyl-L-glutamine-enriched total parenteral nutrition maintains small intestine gut-associated lymphoid tissue and upper respiratory tract immunity. J Parenter Enteral Nutr. 1998;22(1):31-36. doi: 10.1177/014860719802200131

17. Xu CL, Sun R, Qiao XJ, Xu CC, Shang XY, Niu WN. Protective effect of glutamine on intestinal injury and bacterial community in rats exposed to hypobaric hypoxia environment. World J Gastroenterol 2014; 20(16): 4662-4674. doi: 10.3748/wjg.v20.i16.4662

18. Daniele B, Perrone F, Gallo C, Pignata S, De Martino S, De Vivo R, Barletta E, Tambaro R, Abbiati R, D'Agostino L. Oral glutamine in the prevention of fluorouracil induced intestinal toxicity: a double blind, placebo controlled, randomised trial. Gut. 2001;48:28-33. http://dx.doi.org/10.1136/gut.48.1.28

19. Hensley CT, Wasti AT, DeBerardinis RJ. Glutamine and cancer: cel biology, physiologym and clinical opportunities. J Clin Invest. 2013; 123(9): 3678-3684. doi: 10.1172/JCI69600

20. Nakazato M, Hashimoto K, Schmidt U, Tchanturia K, Campbell IC, Collier DA, Iyo M, Treasure J. Serum glutamine, set-shifting ability and anorexia nervosa. Ann Gen Psychiatry. 2010;9:29. doi: 10.1186/1744859X-9-29.

21. Viggiano E, Passavanti MB, Pace MC, Sansone P, Spaziano G, Viggiano A, Aurilio C, Monda M, Vigianno A, Pota V, De Luca B, De Luca E. Plasma glutamine decreases immediately after surgery and is related to incisiveness. J Cell Physiol. 2012;227(5):1988-1991. doi: 10.1002/jcp.22928. 
22. Pan YP, Chang PH, Fan CW, Tseng WK, Huang JS, Chen CH, Chou WC, Wang CH, Yeh KY. Relationship between pre-treatment nutritional status, serum glutamine, arginine levels and clinicopathological features in Taiwan colorectal cancer patients. Asia Pac J Clin Nutr. 2015;24(4):598-604. doi: 10.6133/apjen.2015.24.4.23.

23. Magalhaes CR, Malafaia O, Torres OJ, Moreira LB, Tefil SC, Pinherio Mda R, Harada BA. Liver regeneration with l-glutamine supplemented diet: experimental study in rats. Rev Col Bras Cir. 2014;41(2):117-121.

24. Poschke I, Mao Y, Kiessling R, de Boniface J. Tumor-dependent increase of serum amino acid levels in breast cancer patients has diagnostic potential and correlates with molecular tumor subtypes. J Transl Med. 2013;11:290. doi: 10.1186/1479-5876-11-290.

25. Yue C, Tian W, Wang W, Huang Q, Zhao R, Zhao Y, Li Q, Li J. The impact of perioperative glutaminesupplemented parenteral nutrition on outcomes of patients undergoing abdominal surgery: a metaanalysis of randomized clinical trials. Am Surg. 2013;79(5):506-513.

26. Strzelczyk J., Wasiak J., Modzelewski B. Monitoring of C-reactive protein for early detection of complications after surgery. Pol Przegl Chir. 1994;66,4: 352-357. 